Cijin J. George ${ }^{1}$, Sougata Santra ${ }^{2}$, G. V. Zyryanov ${ }^{2,3}$, Kousik Giri ${ }^{1^{\star}}$

${ }^{1}$ Department of Computational Sciences, Central University of Punjab, Bathinda, Punjab, India ${ }^{2}$ Department of Organic and Biomolecular Chemistry, Chemical Engineering Institute, Ural Federal University, 19 Mira St., Ekaterinburg, 620002, Russian Federation ${ }^{3}$ I. Ya. Postovskiy Institute of Organic Synthesis, Ural Branch of the Russian Academy of Sciences, 22 S. Kovalevskoy St., Ekaterinburg, 620219, Russian Federation ${ }^{\star}$ E-mail: kousikgiri@gmail.com

\title{
Arsenate and Arsenite Reaction Kinetics with Ferric Hydroxides Using Quantum Chemical Calculations
}

The knowledge of the mechanism involved in the process of adsorption and desorption of arsenate and arsenite with ferric hydroxides is important to address the water toxicity problems and to tackle the adverse effect of these substances in nature. An essential outcome of previous studies on the kinetics of the arsenate adsorption on aluminum and iron oxide was that the adsorption is a two-phase (bi-phase) process. Quantum mechanical calculations using density functional theory were used to determine the thermodynamic variables governing the adsorption process to get an insight into the stability of the complexes formed. The previous investigation showed that the positively charged ferric hydroxide cluster had better stability at neutral $\mathrm{pH}$. The chemisorbed charged monodentate complexes had Gibbs free energy of reaction $-55.97 \mathrm{kcal} / \mathrm{mol}$ where the bidentate complex formation had Gibbs free energy of reaction $-62.55 \mathrm{kcal} / \mathrm{mol}$. The bidentate complex having a negative charge had more Gibbs free energy of reaction compared to uncharged one. The results of the study indicate that Gibbs free energy for the reaction has a significant role in controlling the kinetics of the adsorption and sorption process of arsenate on ferric hydroxide clusters.

Keywords:

Received: 01.10.2018. Accepted: 25.10.2018. Published: 31.10.2018.

(c) Cijin J. George, Sougata Santra, Zyryanov G. V., Kousik Giri, 2018

\section{Introduction}

Arsenic is a significant contaminant present in the groundwater due to natural processes like weathering of rocks, discharge of effluents and waste disposal from industries, arsenical herbicides and pesticides used in agricultural activities and many other sources [1]. The various oxidation states arsenic exhibits are $-3,0$, +3 , and +5 , where the inorganic forms +3 (arsenite) and +5 (arsenate) states of As are 
predominant depending on the reducing and oxidizing conditions, respectively. The relatively strong adsorption affinity of As shown towards ferric hydroxides has a vital role in the detoxification of As, thereby controlling the arsenic water pollution and employed in techniques for purification of drinking water.

Several works were done on the structural determination of arsenate-ferric hydroxide complex. The studies of arsenic (III) stability on goethite using X-ray absorption spectroscopy and batch techniques indicated that there is inner sphere bidentate complexation through ligand exchange [2]. Monodentate and bidentate complexes are observed in the adsorption of arsenate on goethite [3-5]. The models produced by molecular modeling and the $\mathrm{X}$-ray absorption fine structure spectroscopy (EXAFS) results are compared, and the nature of the chemisorption complex is determined [6,7]. An essential outcome of previous studies on the kinetics of the arsenate adsorption on aluminum and iron oxide was the two-phase adsorption process constituting a fast phase of the time order of a minute or less and slow phase which attains an equilibrium within a time scale greater than 162 hours [5, 8-10]. The factors responsible for this phenomenon are considered to be slow diffusion mass transport $[9,11,12]$, availability of heterogeneous sites, monodentate to bidentate complex conversions, the surface precipitate formation and the rearrangement of surface complexes. Further, the studies on the arsenate desorption by use of different extractants like phosphate or high $\mathrm{pH}$ solutions indicate a slow release of arsenate from the adsorbed complexes. The conclusion from these studies implies that only a small portion of arsenate is released by the use of extractants like phosphate or hydroxide ions. This leads to the interesting fact that a part of arsenate-ferric hydroxide complex may be irreversible in nature.

Despite the studies done on arsenateferric hydroxide complex formation, a little is known about the mechanism of this reaction. In this regard, the motive of this theoretical study is to get an insight into the mechanism governing the arsenateferric hydroxide complex formation. The thermodynamic parameters and reaction rates governing the mechanism are determined by quantum chemical calculations.

\section{Materials and Methods}

All calculations were carried out using the Gaussian 09 software [13]. Full geometry optimizations and corresponding harmonic vibrational frequency computations, to confirm their minima on the potential energy surface, were carried out using the Austin-Frisch-Petersson functional with dispersion (APFD) [14] and M06 hybrid functional of Truhlar and Zhao [15] suite of density functional theories (DFT) as implemented in Gaussian 09. APFD functional has been used as a primary method in Gaussian 09 for its best trade-off

between accuracy and computational cost for the largest range of molecular systems and chemical problems. M06 functional perform better for a model system with dispersion and ionic hydrogen-bonding interactions. For both structural optimizations and frequency calculations the balanced basis set of triple zeta valence from Ahlrichs and coworkers (DEF2TZVP) [16] was employed. For all calculations, solvent effects of water were introduced using the polarizable continuum model (PCM) using the integral equation formalism variant 
(IEFPCM) with APFD functional and the SMD variation of IEFPCM of Truhlar and workers with M06 functional.

Quantum-chemical calculations involving DFT were used to calculate the heat of formation of reactants and products and their corresponding Gibbs free energies. The ferric hydroxides clusters were modeled following the previous studies. The ferric hydroxides clusters consisted of two iron atoms, ten oxygen atoms which were octahedrally coordinated to the iron atoms. The clusters can be represented by the general formula $\mathrm{Fe}_{2} \mathrm{O}_{3}\left(\mathrm{H}_{2} \mathrm{O}\right)_{7}$. The numbers of the protons were varied to calculate the effect of binding of arsenate with the cation and anion cluster's binding sites.
To minimize the effect of gross distortions of the di-octahedral geometry observed in previous studies [17], the coordinates of six peripheral oxygen atoms which were not part of the binding reaction was fixed to simulate the binding sites of the iron hydroxide clusters also including bound arsenic species. The enthalpies of the reaction are determined by calculating the heats of formation. The equation used is as follows:

$$
\begin{gathered}
\Delta_{r} H_{0}(298 \mathrm{~K})= \\
=\Sigma\left(E_{0}+H_{\text {corr }}\right)_{\text {products }}-\left(E_{0}+H_{\text {corr }}\right)_{\text {reactants }}
\end{gathered}
$$

Similarly, Gibbs free energy change of the reaction is computed by the key equation:

$$
\begin{gathered}
\Delta_{r} G_{0}(298 \mathrm{~K})= \\
=\Sigma\left(E_{0}+G_{\text {corr }}\right)_{\text {products }}-\left(E_{0}+G_{\text {corr }}\right)_{\text {reactants }}
\end{gathered}
$$

\section{Results and Discussion}

The heat of formation of the clusters at $0 \mathrm{~K}$ was determined and is given in Table 1 .

Calculated heat of formation Table 1

for three different possible species

\begin{tabular}{c|c|c}
\hline Cluster & Charge & $\begin{array}{c}\text { Heat of Formation } \\
(\mathrm{kcal} / \mathrm{mol})\end{array}$ \\
\hline $\mathrm{Fe}_{2} \mathrm{O}_{10} \mathrm{H}_{13}{ }^{-}$ & -1 & -1261.64 \\
\hline $\mathrm{Fe}_{2} \mathrm{O}_{10} \mathrm{H}_{14}$ & 0 & -1186.33 \\
\hline $\mathrm{Fe}_{2} \mathrm{O}_{10} \mathrm{H}_{15}{ }^{+}$ & +1 & -1087.94
\end{tabular}

The results indicate that the heat of formation of the positive charged ferric hydroxide has the least value at $0 \mathrm{~K}$, whereas the other clusters are more stable than $\mathrm{Fe}_{2} \mathrm{O}_{10} \mathrm{H}_{15}{ }^{+}$. The previous investigation showed that the positively charged ferric hydroxide cluster had better stability at neutral $\mathrm{pH}$ [17]. This may be possible due to the better stabilization of the $\mathrm{Fe}_{2} \mathrm{O}_{10} \mathrm{H}_{15}{ }^{+}$ at neutral $\mathrm{pH}$ and hence increase in the heat of formation at the neutral $\mathrm{pH}$. The optimized geometry of the $\mathrm{Fe}_{2} \mathrm{O}_{10} \mathrm{H}_{15}{ }^{+}$is represented by Fig. 1 .
The reaction of $\mathrm{Fe}_{2} \mathrm{O}_{10} \mathrm{H}_{15}{ }^{+}$with $\mathrm{HAsO}_{4}{ }^{2-}$ resulted in the formation of charged $(-1$ charge) monodentate (Fig. 2) and bidentate complex (Fig. 3).

Meanwhile, the reaction of $\mathrm{Fe}_{2} \mathrm{O}_{10} \mathrm{H}_{15}{ }^{+}$ with $\mathrm{H}_{2} \mathrm{AsO}_{4}$-resulted in the formation of uncharged monodentate (Fig. 4) and bidentate complex (Fig. 5).

The corresponding Gibbs free energy for the reaction was determined for the monodentate and bidentate complexes formed. The values are in given in table two and three, respectively.

The mono- and bidentate complex bearing a negative charge showed higher stability than the uncharged complexes formed. This indicates that the charge on the species improved the stability of the complex. The chemisorbed charged monodentate complexes had Gibbs free energy of reaction $-55.97 \mathrm{kcal} / \mathrm{mol}$, whereas the bidentate complex formation had Gibbs free energy of reaction $-62.55 \mathrm{kcal} / \mathrm{mol}$. Thus, the desorption process of arsenate with com- 
petitive ligands would depend on Gibbs free energy of the reaction. The process is feasible only when the higher Gibbs free energy values are attained. The results of the study indicate that Gibbs free energy for the reaction has a significant role in controlling the kinetics of the adsorption and sorption process of arsenate on ferric hydroxide clusters.

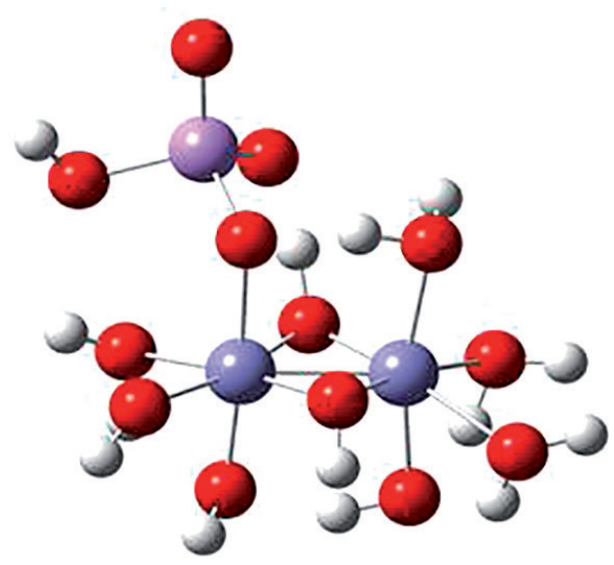

Fig. 2. Structure of negatively charged monodentate complex

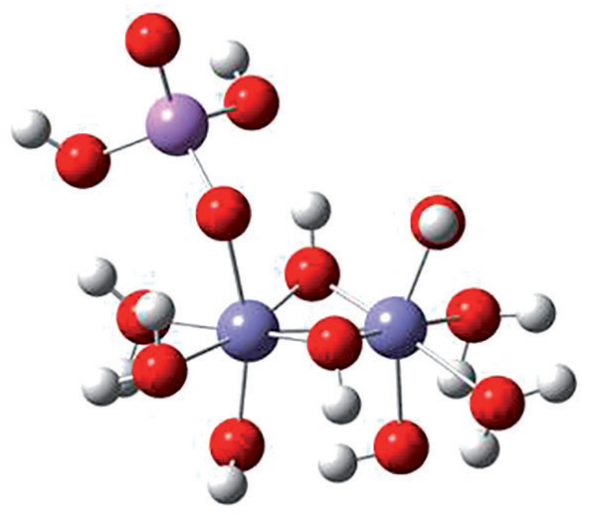

Fig. 4. Structure of uncharged monodentate complex

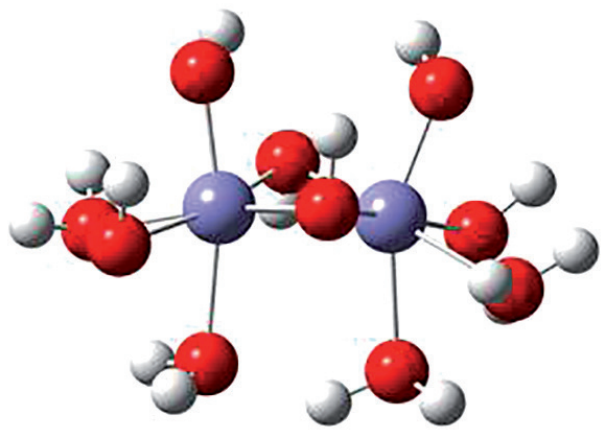

Fig. 1. Structure of $\mathrm{Fe}_{2} \mathrm{O}_{10} \mathrm{H}_{15}{ }^{+}$complex carrying a net positive charge

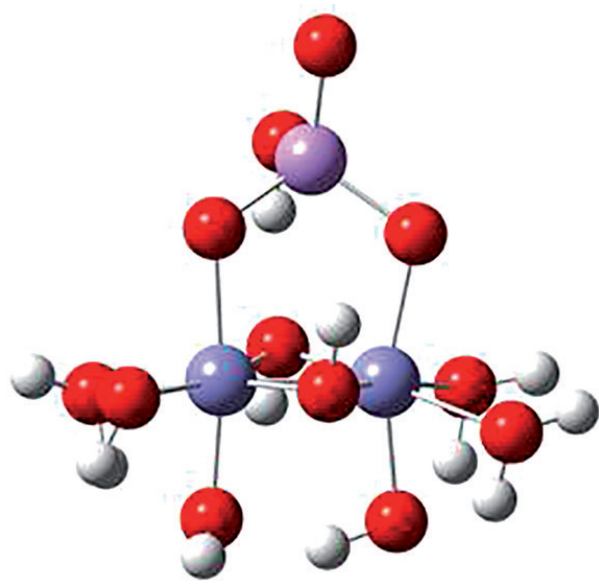

Fig. 3. Structure of negatively charged bidentate complex

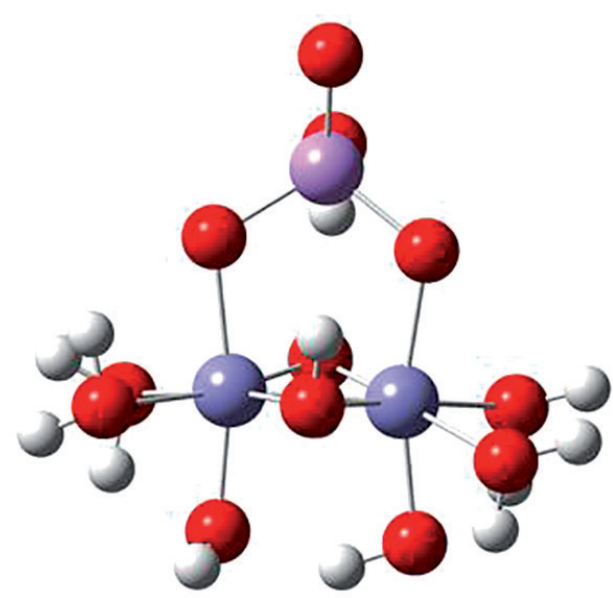

Fig. 5. Structure of uncharged bidentate complex 
Table 2

Thermochemical analysis of negatively charged monodentate and bidentate complexes

\begin{tabular}{c|c|c|c|c|c|c}
\hline \multirow{2}{*}{ Method } & \multicolumn{3}{|c|}{ Product I-Mono Dentate } & \multicolumn{3}{c}{ Product-II Bidentate } \\
\cline { 2 - 7 } & $\begin{array}{c}\Delta_{r} E \\
\mathrm{kcal} / \mathrm{mol})\end{array}$ & $\begin{array}{c}\Delta_{r} H \\
(\mathrm{kcal} / \mathrm{mol})\end{array}$ & $\begin{array}{c}\Delta_{r} G \\
(\mathrm{kcal} / \mathrm{mol})\end{array}$ & $\begin{array}{c}\Delta_{r} E \\
(\mathrm{kcal} / \mathrm{mol})\end{array}$ & $\begin{array}{c}\Delta_{r} H \\
(\mathrm{kcal} / \mathrm{mol})\end{array}$ & $\begin{array}{c}\Delta_{r} G \\
(\mathrm{kcal} / \mathrm{mol})\end{array}$ \\
\hline APFD & -61.3202283 & -106.9803296 & -55.9700823 & -57.8908889 & -57.0832842 & -62.5564221 \\
\hline M06 & & & & -30.9876741 & -30.0162894 & -36.3949235
\end{tabular}

Table 3

Thermochemical analysis of uncharged monodentate and bidentate complexes

\begin{tabular}{c|c|c|c|c|c|c}
\hline \multirow{2}{*}{ Method } & \multicolumn{3}{|c|}{ Product I-Mono Dentate } & \multicolumn{3}{c}{ Product-II Bidentate } \\
\cline { 2 - 7 } & $\begin{array}{c}\Delta_{r} E^{0} \\
(\mathrm{kcal} / \mathrm{mol})\end{array}$ & $\begin{array}{c}\Delta_{r} H \\
(\mathrm{kcal} / \mathrm{mol})\end{array}$ & $\begin{array}{c}\Delta_{r} G \\
(\mathrm{kcal} / \mathrm{mol})\end{array}$ & $\begin{array}{c}\Delta_{r} E \\
(\mathrm{kcal} / \mathrm{mol})\end{array}$ & $\begin{array}{c}\Delta_{r} H \\
(\mathrm{kcal} / \mathrm{mol})\end{array}$ & $\begin{array}{c}\Delta_{r} G \\
(\mathrm{kcal} / \mathrm{mol})\end{array}$ \\
\hline APFD & -32.0525578 & -31.7544907 & -28.0741475 & -38.3383204 & -37.5514235 & -43.1638684 \\
\hline M06 & -16.7174805 & -15.8289271 & -13.6307614 & -20.3865286 & -18.4719972 & -27.6141831
\end{tabular}

\section{Acknowledgments}

K. Giri acknowledges financial support from UGC, Govt. of India for Start-up Project Funding. S. Santra and G. V. Zyryanov thank Russian Science Foundation (Ref \# 18-73-00301) for financial help.

\section{References}

1. Bhumbla DK, Keefer RF. Arsenic mobilization and bioavailability in soils. Arsenic in the Environment. Part I: Cycling and Characterization. Nriagu JO, Editor. John Wiley \& Sons: New York, 1994. pp 51-82.

2. Manning BA, Fendorf SE, Goldberg S. Surface Structures and Stability of Arsenic (III) on Goethite: Spectroscopic Evidence for Inner-Sphere Complexes. Environmental Science \& Technology. 1998;32(16):2383-8. DOI: 10.1021/es9802201.

3. Waychunas GA, Davis JA, Fuller CC. Geometry of sorbed arsenate on ferrihydrite and crystalline $\mathrm{FeOOH}$ : Re-evaluation of EXAFS results and topological factors in predicting sorbate geometry, and evidence for monodentate complexes. Geochimica et Cosmochimica Acta. 1995;59 (17):3655-61. DOI: 10.1016/0016-7037(95) 00276-6.

4. Waychunas GA, Rea BA, Fuller CC, Davis JA. Surface chemistry of ferrihydrite: Part 1. EXAFS studies of the geometry of coprecipitated and adsorbed arsenate. Geochimica et Cosmochimica Acta. 1993;57(10):2251-69. DOI: 10.1016/0016-7037(93)90567-G.

5. Grossl PR, Eick M, Sparks DL, Goldberg S, Ainsworth CC. Arsenate and Chromate Retention Mechanisms on Goethite. 2. Kinetic Evaluation Using a Pressure-Jump Relaxation Technique. Environmental Science \& Technology. 1997;31(2):321-6. DOI: 10.1021/es9506541.

6. Kubicki JD. Comparison of As (III) and As (V) Complexation onto Al- and Fe-Hydroxides. Advances in Arsenic Research. ACS Symposium Series. 915: American Chemical Society; 2005. p. 104-17. 
7. Sherman DM, Randall SR. Surface complexation of arsenic (V) to iron (III) (hydr) oxides: structural mechanism from ab initio molecular geometries and EXAFS spectroscopy. Geochimica et Cosmochimica Acta. 2003;67(22):4223-30. DOI: 10.1016/S0016-7037(03)00237-0.

8. Zhang H, Selim HM. Kinetics of Arsenate Adsorption-Desorption in Soils. Environmental Science \& Technology. 2005;39(16):6101-8. DOI: 10.1021/es050334u.

9. Fuller CC, Davis JA, Waychunas GA. Surface chemistry of ferrihydrite: Part 2. Kinetics of arsenate adsorption and coprecipitation. Geochimica et Cosmochimica Acta. 1993;57(10):2271-82. DOI: 10.1016/0016-7037(93) 90568-H.

10. Yang W, Zhao N, Zhang N, Chen W, Kan AT, Tomson MB. Time-dependent adsorption and resistant desorption of arsenic on magnetite nanoparticles: kinetics and modeling. Desalination and Water Treatment. 2012;44(1-3):100-9. DOI: 10.1080/19443994.2012.691808.

11. Raven KP, Jain A, Loeppert RH. Arsenite and Arsenate Adsorption on Ferrihydrite: Kinetics, Equilibrium, and Adsorption Envelopes. Environmental Science \& Technology. 1998;32 (3):344-9. DOI: 10.1021/es970421p.

12. Luengo C, Brigante M, Avena M. Adsorption kinetics of phosphate and arsenate on goethite. A comparative study. Journal of Colloid and Interface Science. 2007;311(2):354-60. DOI: https://doi.org/10.1016/j. jcis. 2007.03.027.

13. Austin A, Petersson GA, Frisch MJ, Dobek FJ, Scalmani G, Throssell K. A Density Functional with Spherical Atom Dispersion Terms. Journal of Chemical Theory and Computation. 2012;8(12):4989-5007. DOI: 10.1021/ct300778e.

14. Gaussian09, Revision D. 01, Gaussian, Inc., Wallingford CT, 2013.

15. Zhao Y, Truhlar DG. The M06 suite of density functionals for main group thermochemistry, thermochemical kinetics, noncovalent interactions, excited states, and transition elements: two new functionals and systematic testing of four M06-class functionals and 12 other functionals. Theoretical Chemistry Accounts. 2008;120(1):215-41. DOI: 10.1007/s00214-007-0310-x.

16. Weigend F, Ahlrichs R. Balanced basis sets of split valence, triple zeta valence and quadruple zeta valence quality for $\mathrm{H}$ to $\mathrm{Rn}$ : Design and assessment of accuracy. Phys Chem Chem Phys. 2005;7(18):3297-305. DOI: 10.1039/B508541A.

17. Farrell J, Chaudhary BK. Understanding Arsenate Reaction Kinetics with Ferric Hydroxides. Environmental Science \& Technology. 2013;47(15):8342-7. DOI: $10.1021 /$ es4013382. 